\title{
The role of comorbidity in delineating the etiopatomechanism of disease: the co-occurrence of migraine with aura and restless leg syndrome
}

\author{
Terezia Zsombok', Xenia Gonda $2,3^{*}$ \\ From $1^{\text {st }}$ International Congress on Neurobiology and Clinical Psychopharmacology \\ and European Psychiatric Association Conference on Treatment Guidance \\ Thessaloniki, Greece. 19-22 November 2009
}

\section{Background}

The etiology and patomachanism of migraine is not yet fully understood. This may be related to the fact that the eitopathology of disorders comorbid with migraine (depression, restless leg syndrome) is also not fully known. The common well-known syndromes of migraine attack include nausea, vomiting, drowsiness, and its comorbidity with restless leg syndrome (RLS) and related neurogenetic and neurochemical research in the past years led to the proposal of the pathogenetic role of the dopaminergic system in the development of migraine. RLS affects about $10-15 \%$ of USA population and shows a $17 \%$ comorbidity with migraine. RLS is a sensomotor disorder showing a circadian pattern which worsens in a quiet awake state (especially around falling asleep). Often a permanent sleep-wake disorder develops with mental and affective disturbances. The origin of RLS is idiopathic in $30-40 \%$ of cases but it can also be familiar. In the background of secunder RLS there is often iron deficiency periferal neuropahty, uraemia, rheumatoid arthiritis, diabetes, etc is present. Pregnancy and hormonal symptoms may also enhance the symptoms. The treatment is complex: pharmacological and non-pharmacological therapy.

We would like to present the case of a 57 year old woman who suffers from migraine with visual aura since her young adulthood and from restless leg syndrome since the age of 48 , together with relevant literature data. She sought medical and psychological help for her sleep-wake disturbances, affective symptoms and deterioriating quality of life present in the last few years.

\footnotetext{
${ }^{2}$ Department of Clinical and Theoretical Mental Health, Faculty of Medicine,
} Semmelweis University, Budapest, Hungary

\section{Author details}

${ }^{1}$ Department of Clinical Psychology, Faculty of Medicine, Semmelweis University, Budapest, Hungary. ${ }^{2}$ Department of Clinical and Theoretical Mental Health, Faculty of Medicine, Semmelweis University, Budapest, Hungary. ${ }^{3}$ Department of Pharmacology and Pharmacotherapy, Faculty of Medicine, Semmelweis University, Budapest, Hungary.

Published: 22 April 2010

doi:10.1186/1744-859X-9-S1-S207

Cite this article as: Zsombok and Gonda: The role of comorbidity in delineating the etiopatomechanism of disease: the co-occurrence of migraine with aura and restless leg syndrome. Annals of General Psychiatry 2010 9(Suppl 1):S207.
Submit your next manuscript to BioMed Central and take full advantage of:

- Convenient online submission

- Thorough peer review

- No space constraints or color figure charges

- Immediate publication on acceptance

- Inclusion in PubMed, CAS, Scopus and Google Scholar

- Research which is freely available for redistribution

Submit your manuscript at www.biomedcentral.com/submit
Biomed Central 